\title{
Cutaneous Larva Migrans
}

\author{
Takahiro Matsuo ${ }^{1}$, Toshiaki Nakano ${ }^{1}$, and Nobuyoshi Mori ${ }^{1}$ \\ ${ }^{1}$ St Luke's International University
}

January 29, 2021

Cutaneous Larva Migrans

Takahiro Matsuo M.D. ${ }^{1}$, Toshiaki Nakano M.D. ${ }^{2}$, Nobuyoshi Mori M.D. ${ }^{1}$

${ }^{1}$ Department of Infectious Diseases, St. Luke's International Hospital, Tokyo, Japan

${ }^{2}$ Department of Dermatology, St. Luke's International Hospital, Tokyo, Japan

Keywords: cutaneous larva migrans, bilateral, hookworm

Total word count: 99 words

\section{Key Clinical Message:}

Clinicians should consider hookworm-related cutaneous larva migrans in travelers from endemic areas with skin lesions with pruritic, serpiginous, and subcutaneous track, since some may develop bacterial superinfection and Loeffler's syndrome.

\section{Corresponding author:}

Takahiro Matsuo, MD

Department of Infectious Diseases, St. Luke's International Hospital, Tokyo, Japan

9-1, Akashi-cho, Chuo-ku, Tokyo, Japan. Tel: +81-3-3541-5151; Fax: +81-3-3544-0649

E-mail:tmatsuo@luke.ac.jp

A previously healthy 24-year-old American man, a returning traveler from Tanzania presented to our hospital with deteriorating pruritic meandering erythema on bilateral soles for 10 days (Picture 1A, 1B). He had an episode of walking barefoot on the beach during the trip. On exams, he was noted to have elevated, serpiginous, and reddish-brown tracks on his bilateral foot $(2-3 \mathrm{~mm}$ in width and $5 \mathrm{~cm}$ in length), which were consistent with cutaneous larva migrans. We performed incisional biopsy and started oral ivermectin $0.2 \mathrm{mg} / \mathrm{kg} /$ day for 2 days. The patient's condition improved without any complication. Three-month later, we confirmed the resolution of these tracks.

Hookworm-related cutaneous larva migrans (HrCLM) is caused by penetration and migration in the epidermis of the larva of nematodes. The most common parasite species are Ancylostoma brasiliense, Ancylostoma caninum, and Necator americanus [1]. Although HrCLM resolves spontaneously after a few weeks to months, with ivermectin or albendazole complete remission is observed within 1 week [2]. Some patients may have persistent discomfort, secondary bacterial infection and Loeffler's syndrome, which is pulmonary infiltration with peripheral eosinophilia. We should consider HrCLM in patients with these skin lesions from endemic areas.

Figure legend 
Figure 1A, B. Elevated, serpiginous, and reddish-brown tracks on his bilateral foot Acknowledgement

None

\section{Reference}

1. Heukelbach J, Feldmeier H. Epidemiological and clinical characteristics of hookworm-related cutaneous larva migrans. Lancet Infect Dis. 2008;8(5):302-9.

2. Kincaid L, Klowak M, Klowak S, Boggild AK. Management of imported cutaneous larva migrans: A case series and mini-review. Travel Med Infect Dis. 2015;13(5):382-7.

\section{Authorship List:}

Author contributions:

Nobuyoshi Mori: He assisted in the preparation of the manuscript.

Toshiaki Nakano: He assisted in the preparation of the manuscript.

\section{Conflict of Interest Statement:}

Nothing to declare

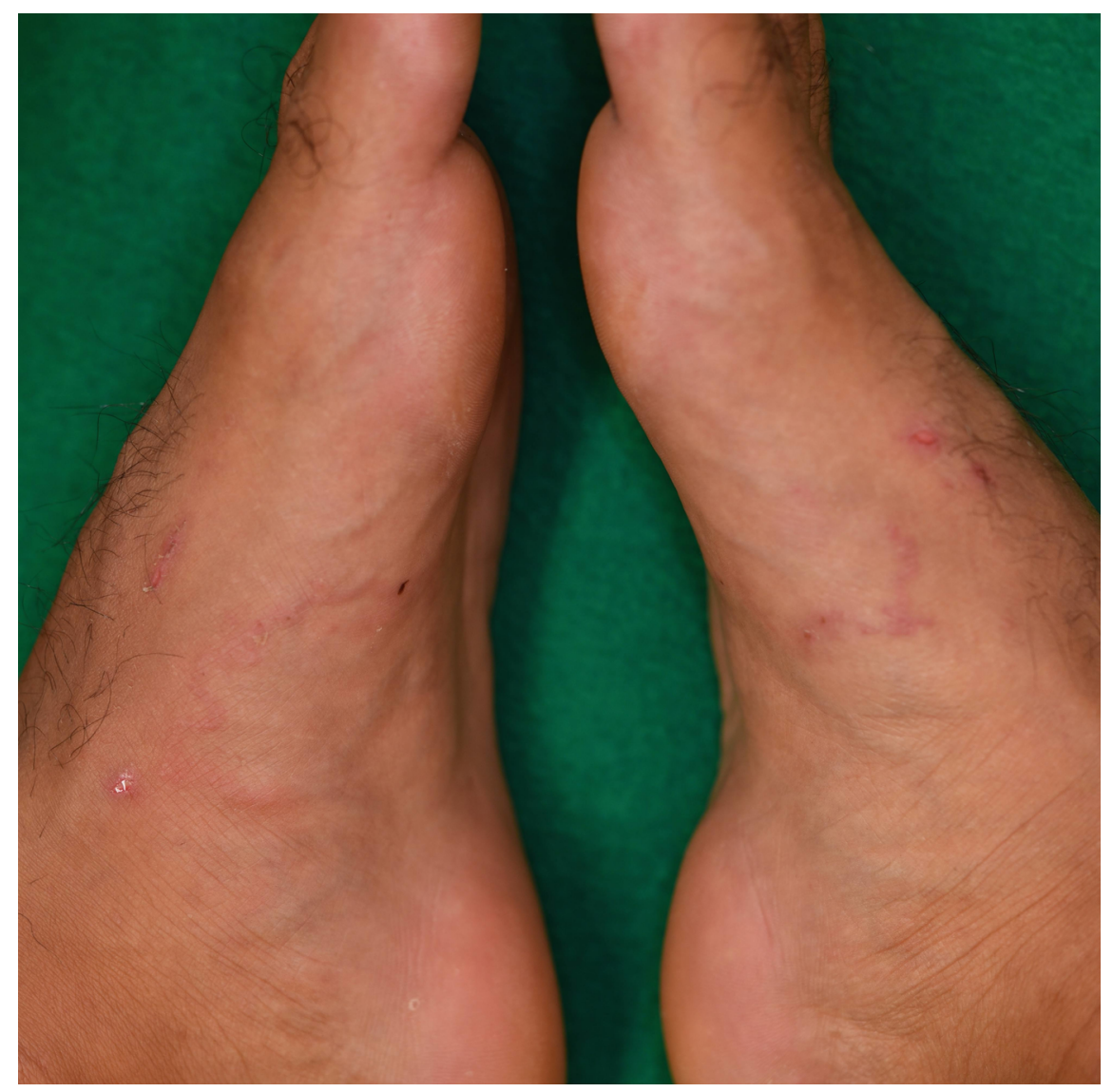




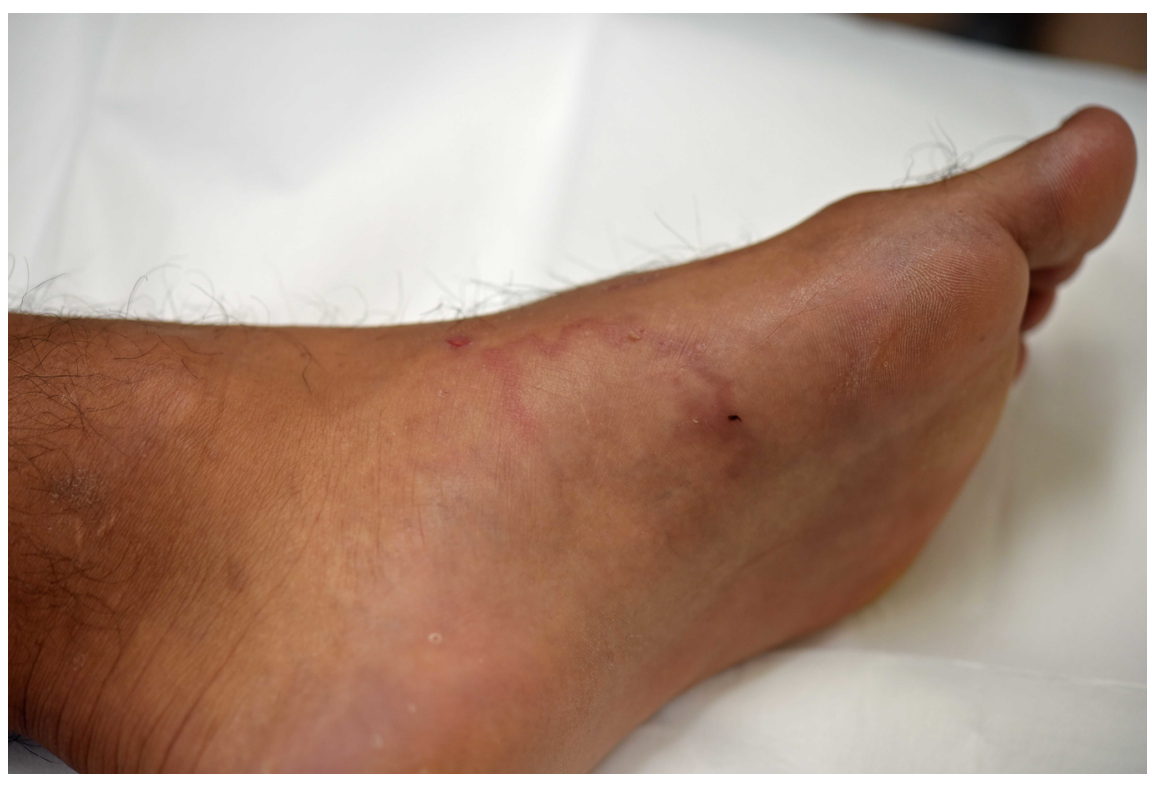

